\title{
1 Scientific and democratic relevance of RRI
}

\author{
Dimensions and relations
}

Robert Gianni

\subsection{Introduction}

Responsible Research and Innovation (RRI) has gained prominence in the academic debate in the last decade. Introduced in order to provide an operational framework for enabling communication between science and society, it has undergone a consistent number of analyses to understand its value and relevance for such operation (Burget et al. 2017). However, despite this large number of attempts, clarity about its efficacy is still far from being reached. Accordingly, initial enthusiasm has started to fade in favor of alternative, more specific regulatory measures. This chapter aims to evaluate the scientific and democratic relevance of RRI beyond skepticism about the acronym, in order to understand if it can still play a role in the dialogue between science and society.

In order to do so I will operate an analysis, on the basis of a pragmatist perspective, of the main features and challenges faced by science and democracy, in order to then extract their main objectives and principles. I will then introduce the evaluation phase with a brief analysis of the concept of responsibility so to offer a theoretical background that summarizes the dynamic nature of RRI. One of the puzzling aspects of RRI is in fact the difficulty to obtain a common understanding on what responsibility means and implies. This preliminary assumption appears often fragmented or controversial, making it difficult to obtain a homogeneous approach to RRI. In a following step, I will then be able to start the evaluation of the scientific and democratic relevance of RRI. In order not to lose the conceptual power of the principles embedded in the framework, instead of concentrating on the acronym, I will focus on the six keys (engagement, gender, open access, science education, ethics, governance) adopted by the European Commission (EC), which will reasonably last even beyond RRI. It will finally emerge that RRI has a high scientific and democratic relevance.

\subsection{Science and society}

When it comes to RRI, one of the most intuitive doubts is about the capacity of an ethical framework to increase or at least maintain the scientific 


\section{Robert Gianni}

relevance of research and innovation. Scientists and innovators might still believe that a pure technical process, one apparently devoid of any extra scientific consideration, can represent an efficient methodology to make their research progress. Even amongst those who are not explicitly supporters of technological determinism, it is possible to find caution about the value of a non-technical integration into the research process, at least at an earlier stage.

It would be hard to affirm that technology, and science more generally, does not have an impact on societies. ${ }^{1}$ The intuition of Poincaré, demonstrated only much later by Edward Lorenz, that an infinitesimal variation has potentially infinite sets of consequences, has nowadays become evident also to non-specialists (Jasanoff 2016; Lorenz 1963; Turing 1950).2 Besides, studies on complexity have demonstrated how linear models are not apt to explain effects springing from systems behavior (Bridgman 1927). The "butterfly effect" is exactly what poses scientists with challenges that are not only technical, but ethical and, in the end, political.

It is difficult not to recognize that current societies and thus scientific research are complex and have to deal with a growing "hyper-complexity" (Qvortrup 2003). According to Funtowicz and Ravetz (1993), science is now developed in a "post-normal" scenario. For Gorgoni (2018), the intensification of consequences in terms of both time and space has shifted foresight exercises from dealing with uncertainty to navigating in indeterminacy. The transition from a curiosity-driven method to a problem-oriented one, where knowledge and decisions are not detachable, together with the growth of complexity, has made it difficult to exclude values and interests from scientific research (Arnaldi \& Bianchi 2016; Funtowicz \& Ravetz 2008; Jasanoff 2004).

Following this path, some authors have pointed out that science not only has an indirect and unforeseeable impact on society, but is also a sociopolitical construct. Accordingly, the objectives of scientific research, or rather their topics, are always decided according to political decisions although these are often implicit (Jasanoff 2004, 2016; Wynne 1993).

From a more radical point of view, the relation between nature and society is a coproduction, determining that our representations are inseparable from the ways in which we live (Pellizzoni 2004).

Many authors have justified the necessity to include extra-technical aspects by enumerating recent cases that have generated outrage in public opinion. They have shown the potentially severe consequences that could occur when neglecting a broader perspective in the choice of scientific paths. Several negative examples, like genetically modified organisms, or other episodes connected to chemicals, have shown the limits of adopting a purely quantitative methodology for assessing the impact of a research product (Jasanoff 2016; Von Schomberg 2013, 2014). Besides, many of these events suggest that consequences are often considered to be bad not only in terms of safety, but according to hybrid, dynamic and sociotechnical aspects (Jasanoff 2016). The risks stemming from the bureaucratization of thought 
and the supremacy of technique over politics urge us to focus on humanistic and social ends (Horkheimer \& Adorno 2002).

Technology and science more generally are artifacts that confront humans with new challenges and possibilities. Emerging technologies like artificial intelligence, genomics or synthetic biology are fascinating gamechangers in the future of humanity. ${ }^{3}$ However, Dewey reminds us that scientific artifacts are not simply there in some kind of naturalistic or deterministic fashion; they are the results of interactions - socially conditioned phenomena resulting from accumulated culture (Dewey 1991, Ch. 3). To paraphrase the American philosopher, we do not naturally need them, but we want them (p. 106). Therefore, also the assessment of emerging technologies becomes more complex and needs to take into account a broader "range of values that humans care about when contemplating the future" (Jasanoff 2016, p. 58). Also for Funtowicz and Ravetz (1993), in a situation of post-normal science, and in order to deal with the major challenges arising in our societies, the epistemic dimension should be integrated with an axiological one, meaning that values should complement technical aspects.

Apart from the easily understandable reactions to negative episodes, though, it is important to put in evidence that science has a proactive power in increasing the well-being of humankind. In a recent analysis, Jasanoff has stated that technologies, as the current focus of science, are "devices with which modern societies explore and create potentially more liberating and meaningful designs for future living” (Jasanoff 2016, p. 242). In this respect, there is a growing amount of literature and evidence about the advantages of the integration of broader perspectives into science. Extending knowledge can bring benefits to scientific investigations because it increases the possibility of solving problems by including additional and new information (Pellizzoni 2004; Stilgoe et al. 2013). Although, as pointed out by Blok and Lemmens (2015), transparency claims can be seen as highly naïve or counterproductive (Blok 2018), it is also true that external information can but enrich the general level of knowledge needed to progress in scientific research and innovation.

It has been noticed that scientific research has consistently turned to a contextualization of knowledge production (Nowotny 2015; Pavie et al. 2014) which is often aimed at the "creation of wealth" (Krishna 2013). In this sense, although basic research still plays a prominent and prestigious role, we do witness a proliferation of small-scale laboratories and research group targeting specific, and often already existing, problems. This is probably due also to the fact that technologies mutate along with the societies in which they operate (Jasanoff 2016). Therefore, it has been shown that successful technologies are often those that adapt and respond to particular needs (Bijker et al. 1987).

A connected reason is the change in the production process, economic growth and the consequent advantages of a "productive" research and innovation process (Godin 2015). According to Blok and Lemmens, "most 


\section{Robert Gianni}

innovations take place in commercial or industrial settings" and products need to be profitable (Blok \& Lemmens 2015, p. 20). Also research increasingly faces challenges arising from the necessity of meeting criteria of excellence that can be measured and that can produce growth. However, Mazzuccato has reminded us that, although this is easily overlooked, private successes often have public origins and therefore researchers and innovators should deal with these political origins (Mazzuccato 2015). What she points out is that often science (and innovation) cannot be totally implemented without a whole series of other inputs and measures often generated by institutional mechanisms, which then raise the question of the criteria for decision-making. The question of "framing" of research trajectory appears for many scholars to be inextricable from the ontology of products and processes (Gianni \& Goujon 2018; Goffman 1974; Maesschalck 2017).

If we recap the different aspects of the question, we can see that nowadays science has to deal with an increasingly growing complexity, which requires innovative, experimental and broader methodologies. This has been practically urged by negative happenings, but also the potential advantages are seen as highly relevant.

The ways in which to implement such broadening are mostly targeting participation and deliberative processes in the wake of democratic models (Guston 2001). Although it might be argued that more innovative and bottom-up instruments are needed (Bucchi \& Neresini 2008; Flipse 2012; Gottweis 2008; Pansera \& Owen 2018), the aim is nevertheless to establish a discussion with a sufficiently extended range of different perspectives, which can then feed the trajectory of science research. The relevance of different angles concerns the quantity of agents potentially affected by the outcomes, as well as the whole "worlds of relevance" of the actors considered (Arnaldi \& Bianchi 2016; Jasanoff 2016; Limoges 1993), and their influence in the decision-making process (Fung 2006; Gianni \& Goujon 2018). The necessity to enlarge perspectives towards narratives is considered to be important to not reduce the inputs in the discussion to "rationalistic" ones, which would fall back into the same limited epistemic framework that they are supposed to abandon (Dewey 1991 [1927]; Funtowicz \& Ravetz 1993; Ricoeur 2000; Wynn1993). However, it has been highlighted that the competence of participants to express their interests is also crucial. This means that they have to be able to adopt a mature view in order to be able to fully understand some of the technical aspects in question (Kitcher 2011). Furthermore, participants should be willing to accept a common set of rules for deliberating (Bohman \& Regh 1997; Fishkin \& Laslett 2003; Hajer \& Wagenaar 2003; Reber 2016). This last indication highlights the necessity to promote bilateral relations between science and democracy. If the former is called to open the discussion on the overall objectives because of endemic and epidemic reasons, the tools pertaining to the latter should also be deployed with a greater scientific attitude. 


\subsection{Democracy: principles, models and methodologies}

Evaluating the democratic relevance of RRI implies an overall judgment of the relation between science and democracy and their possible intersection.

In this regard, it is important to operate a brief examination of the key features of the concept of democracy in order to understand what are the driving principles and its main objectives. In this way we will then be able to compare them with the objectives and tools embedded in RRI.

Democracy is a very complex concept with several ramifications and subgroups. According to Sartori, sticking to a definition or to the etymology of the word would be an error that would disserve rather than serve democracy (Sartori 1987, p. 13). Democracy is a historical model that changes in a perpetual tension between its ideal features and actual reality. The understanding of the demos has changed throughout the centuries according to moral, epistemic and political assumptions. Besides, the increase in complexity, due to the extension and intensification of interactions, has generated the need for increasingly sophisticated and continuously evolving forms (Galli 2011). In this sense, it is difficult to talk of one model of democracy, but rather of an ideal assuming different shapes.

All scholars dealing directly or indirectly with the concept of democracy share the belief that this political model aims to preserve and promote the moral and juridical ideals that found in the French Revolution their most symbolic expression: freedom, equality and solidarity. However, not all agree on the different weight of each principle, or on their relation with the other two.

Some authors have stressed the crucial role of equality (and that of defense from evil power) (Galli 2011). Sartori upholds equality, although a multidimensional one, as the protecting principle against power abuses (Sartori 1987). For Dahl, democracy should rest on the principle of intrinsic equality (Dahl 1989). Other authors, although less directly concerned by the principle and more about the methods through which to attain democratic processes, are also discussing new forms of democracy on the normative basis of equality (Manin 2012). The concept of equality itself is also used in different ways, depending on whether it concerns fundamental rights (Dahl 1989), applied ones, or whether it addresses the actual material conditions of an equal access to the public sphere (Honneth 2014; Sen 1999).

A similar, but perhaps more complex, destiny has characterized the priority given to the concept of freedom. Several scholars have endorsed the distinction proposed by Berlin between a negative and positive understanding of freedom (Berlin 2002). Northern American authors distinguish between freedom as protection from hindrances, and liberty as its institutional implementation (Pitkin 1988). Some philosophers have instead developed a more sophisticated structure for justifying the conceptual priority of freedom over equality (Bourgeois 2017; Honneth 2014; Kitcher 2011). These authors 
share a multilayered understanding of the concept which includes social structures of deliberation. This shared understanding appears to be a solid and updated development of the two meanings of individual freedom as self-determination and self-realization, as delineated respectively by Kant and Herder (Gianni 2018; Hegel 1991 [1821]; Honneth 2014; Kant 1997).

The third ideal, solidarity, has characterized the public debate in a more concrete way, due to its more tangible nature. At the theoretical level we often find it under the vests of redistributive justice, but it is nevertheless considered to be inextricable from a just democratic process (Carrabregu 2016; Dews 1992; Rodotà 2014; Sartori 1987). At a first glance, solidarity is a much more controversial point and it is not conceived as a presupposition but rather as an objective or a balancing force (Dahl 1989).

Although we find different understandings of these principles, democracy is for all of the cited authors the only viable alternative to enforce them.

The appropriate tools that could serve the purpose emerge from the conceptual priority given to one principle and to the diagnosis of its actual enforcement. Accordingly, between the extremes of direct democracy on the one hand, and technocratic (Audard 2009), guardianship (Dahl 1989), or authoritarian democracy (Sartori 1987) on the other hand, we can find a rich galaxy of proposals. Amongst the "theories of democracy in the plural," Holden organizes his analysis around five clusters: radical, new radical, pluralist, elitist and liberal-democratic theory (Holden 1999). Dahl distinguishes between Madisonian, populistic and polyarchal democracy (Dahl 1989). Sartori's account rests on four typologies: electoral, participatory, referendum and competitive, where the "major contrast is rendered in terms of participatory versus competitive theories" (Sartori 1987, p. 14).

Consequently, also the tools activated within these frameworks (and across them) are of various nature. According to a specific perspective, but also to a determined historical moment, the tools have undergone a diachronic and synchronic development (Sintomer 2011). If, on the one hand, some features of democracy have evolved, contributing to its refinement, others, like the mechanism of drawing lots, have gone through a less linear progress (Sintomer 2011). Within the discussion over one conceptual tool, the indications have stressed different aspects. Tools for enhancing direct forms of democracy, for instance, have been encouraged according to refined hybrid formats so to address underrepresentation and disaffection (Manin 2012; Sintomer 2011; Vandamme 2018) or as provocative attempts to encourage a public debate on the subject of democracy itself (Van Reybrouck 2014).

This conceptual universe is fueled by different perspectives being composed by philosophers (Honneth), political scientists (e.g. Sintomer, Dahl and Manin) and historians (Van Reybrouck). These approaches differ in their methodology, objective and normative depth. However, there are some features that crosscut most of these analyses on democracy. Some of the ideal criteria that identify a democratic process are commonly identified with participation, transparency, responsiveness, inclusiveness, deliberation 
and, on a more formal level, balance. According to Sartori and Dahl, these features belong to the ideal (Sartori 1987) or normative (Dahl 1989) sphere of democracy, and they serve as regulatory criteria for their implementation in real or descriptive democracies. The two authors are clear in recognizing the sufferance of democracy in its actual forms but they blame it on the discrepancy between intention and facts. Despite the mistrust that we could have in democracy, they encourage implementation of those criteria to shorten the gap between norms and facts. The distance between the objectives and the reality of the model is what most probably concurs to generate what Galli calls a "discomfort" about democracy (Galli 2011).

It is important to consider these criteria because they are all expressions of what we might conceive as our current reference ideal of democracy. Today's dominant understanding of democracy is one that enables all individuals to express their preferences through mechanisms of deliberation on the basis of mutual respect (Dewey 1991; Reber 2016). Reasons, language, communication and deliberation are not only buzz words which we encounter in political theory or rhetorical slogans, but substantial forms through which citizens can realize their full potential as individuals (Goodin 2012; Honneth 2014). As reminded by Sartori, "Democracy is ... a characteristically flexible system. Above all, or first, democracy is a procedure for processing whatever a society demands, whatever comes up through 'voice' and with voice" (Sartori 1987, p. 77).

We could list several attempts to improve participation and deliberation in democratic processes. They are often experimental because they must deal with the challenges arising from the complexification of the public. The indication to create a community or a "public" (Dewey 1991) in order to discuss general concerns is in itself a challenge to which many scholars are trying to offer an answer (Fagotto \& Fung 2006; Goodin 2012; Hajer \& Wagenaar 2003; Jacquet 2018). However, the basic assumptions rest on the cognitive certainty that, through means of knowledge formation and communication exchanges, democratic processes will help to improve freedom, equality and solidarity.

After having understood the current challenges for scientific investigations and for democratic processes, we can now evaluate if RRI is relevant for the objectives and methodologies required by current scientific and democratic models.

\subsection{Responsible research and innovation features}

If we want to assess the democratic and scientific relevance of RRI, it is important to first agree on one understanding of RRI. Recent literature shows in fact that such an attempt proves to be harder than one could expect ten years after its introduction in the public debate.

Although we might consider its conceptual history fairly dense since its first occurrences in 2008 and 2009 at the academic and national level 
(Robinson 2009), and 2012 at the European level (Pearson 2018), RRI still seems to be far from reaching a clear and shared understanding. Despite the admirable quantity of contributions published so far ${ }^{4}$ (Burget et al. 2017; Goos \& Lindner forthcoming) and notwithstanding the fortune that, although patchworked, it has encountered at the policy level, RRI still represents for many commentators and practitioners more of a riddle than a solution. Furthermore, the initial enthusiasm detectable in academic contributions and policy investments has recently started to fade, although the reasons for such decline are not homogenous. ${ }^{5}$

According to some recent analyses, one of the potential motives can be traced to a general absence of harmony between policy-makers and academics but also within such clusters (Klassen et al. 2018; Wickson \& Forsberg 2015). Pearson has also listed the discrepancies between national funding schemes and that of the EC one, highlighting how such divergence can generate an overall confusion for researchers in the implementation of RRI (Pearson 2018). In the UK, for instance, RRI is often identified with the AREA scheme (anticipate, reflect, engage, act), ${ }^{6}$ while the EC has proposed six thematic keys for its implementation (engagement, gender, science education, open access, ethics, governance). ${ }^{7}$

From another angle, the relation between the academic debate and the policy-makers has suffered from a similar situation. Klassen et al. (2018) have highlighted the lack of communication between the academic debate and the policy-makers at the EC level, with regard to the understanding of RRI. Accordingly, on the one hand, a large part of the academic debate mostly draws on the objectives set in Von Schomberg's definition (Burget et al. 2017) and discusses Stilgoe et al.'s (2013) methodology. On the other hand, the EC has not explicitly integrated academic features in their framework, promoting instead a soft implementation of six thematic keys. Goos and Lindner have noticed "a degree of incongruence between these academic debates and their manifestations at the EC policy level" (Goos \& Lindner forthcoming, p. 7).

The proliferation of definitions that has characterized the development of RRI, although they might be coupled according to their objectives (van den Hoven 2013; van Oudheusden 2014), has most probably also played a slowing-down role in the take-up of common strategies for its actualization.

At a practical level, it emerges that the actual integration of RRI within some research domains has not been successful, although also here the reasons are varied. At project level within the EC funding framework, research results have shown a general inconsistency between overall objectives and common strategies for implementing RRI. If in some program lines RRI has been central, in some it has been overlooked, and others have focused, directly or indirectly, only on some of its features, but not on the notion itself. ${ }^{8}$

In general, this depiction shows that it is at best difficult to agree on a conception of RRI which we could use to assess its scientific and democratic relevance. 
However, despite this methodological complexity, mostly due to a solid epistemic and politic plurality (Reber 2016), it is important to choose one conceptual reference in order to evaluate the scientific and democratic relevance of RRI.

In order to determine our choice, we first need to propose an analysis of the main driver of RRI, responsibility, so as to understand also other aspects connected to the framework that are implicitly driving its tools.

\subsubsection{Responsibility: a multi-level concept responding to historical challenges}

Responsibility is a concept that has grown with the development of agents' interactions amongst themselves and with their external environment. If the very first modern occurrences of the term are strictly connected to a political dimension (McKeon 1957; Rosanvallon 2015), its more refined developments are to be found in the juridical and moral realm (Foddai 2005; Ricoeur 2000; van de Poel 2011).

With regard to the juridical sphere, we can detect a solid deontological tradition, building on Kant's moral and legal doctrines, which finds in legal positivism (and neo-positivism) an important recent doctrine (Hart 2008; Kelsen 2005 [1934]; Paulson 1992). According to this line of thought, responsibility is the legal duty to follow a certain number of rules, laws or principles in order to be active members of a given society. It is in many respects retroactive or focused on the relation that agents hold with their past actions. It usually has a "negative" connotation because it concentrates on the restrictions or sanctions that an individual would encounter in case of fault and is probably still nowadays the most common understanding of it (Moore 1984).

Originally entrenched in the framework of criminal law, this delineation started to be questioned with the development of the production process and the promulgation of civil laws at the beginning of the twentieth century (Ewald 1986). The accent previously placed on the author of an action as accountable and thus punishable was then shifted to the victim in the position to claim for compensation (Ricoeur 2000). This alternative perspective represented a crucial turning point because it concentrated not on the guilty person but on the victim and the damages she could suffer. This ended up overshadowing the connection of an action to an actor and the related notions of fault and punishment in favor of anonymous forms of compensation - usually economic ones (Ricoeur 2000). Driven by the increasing rise of risks and societal claims for security and solidarity, this new understanding aimed at dealing with the emerging impact of technology in societies, which criminal laws could not sufficiently address. This passage has been defined as the one "from individual management of fault to a socialized management of risk" (Engle 1993, p. 16).

However, it has been pointed out that this specific understanding of responsibility embeds severe side effects if detached from the notion of 
imputation and accountability. Ricoeur has shown that, with the extension of the sphere of risks in terms of space and time, the loss of identifiable fault and punishment of the responsible actor can lead to the paradoxical effect of placing actions under the sign of fatalism, which is the opposite of responsibility (Abbagnano 1957; Ricoeur 2000, p. 26). If fault cannot be traced back to an accountable person, then the connection between agents and actions vanishes, generating, as was the case when these laws were promulgated, a system of insurance where there can be a total loss of individual responsibility (Ewald 1986).

If the juridical understanding of responsibility as accountability has slowly shrunk in the philosophical debate, discussions on the moral notion of responsibility have instead proliferated (Pellé \& Reber 2015; Vincent et al. 2011). The first modern occurrences of the moral traits of responsibility can be detected in Kant's moral philosophy, when the German philosopher defined the conditions for attributing an action to an agent and all the moral implications deriving from them. However, also moral responsibility faced the changes of societal interactions already encountered by legal scholars. The main shift, as we have seen, was the one passing from a single individual and her capacity to be held accountable and punished for her actions, to the damages potentially affecting someone external, a vulnerable figure. Then, the opening to the external effects of actions rather than the internal logic for acting generated a withdrawal from the criminal aspects of responsibility and also concurred with a proliferation of its moral features. In moral philosophy this has raised a very complex debate about the means and criteria, but most of all about the object of responsibility. If in civil law the question of detecting the victim is already difficult, in moral philosophy defining sufferance and vulnerability is even more complex (Ricoeur 2000).

Moral responsibility has fundamentally been addressed by two main perspectives. On the one hand, following a Kantian approach, we find scholars analyzing it through the intentions of an agent (Kant 1997). On the other hand, in line with different schools of thought, responsibility is assessed according to the consequences of an action (Pettit 1997). It has been pointed out that the main problem with the former concerns the disconnection between intended and actual effects of an action, which, by underestimating the complex chain of causes and consequences, can disregard the side of the victim and the related sufferance (Williams 1984). The latter, focused on calculating consequences, instead does not often consider the importance of subjective and non-rational values (Sen \& Williams 1982). Furthermore, consequentialism appears to be facing several difficulties in dealing with the challenges connected to complex societies, and the extension, in terms of time and space, of risks (Ricoeur 2000). In fact, from when and until which point, it might be argued, can we consider ourselves responsible for the consequences of our actions? Following Ricoeur, we can recognize the dilemma we are facing when considering that "simply neglecting the 
side-effects of an action would render it dishonest, but an unlimited responsibility would make action impossible" (Ricoeur 2000, p. 33).

It is not by chance then that more recently a third stream has tried to address this dilemma between intentionality and externalities by encouraging an existential imperative of responsibility conceived as care (Grinbaum \& Groves 2013; Jonas 1984). Given the uncertainty about the future and the increasingly growing influence of technologies in life as such, responsibility has started to address the necessity to take care of our "environment" in similar ways as we would take care of our beloved ones (Pavie 2018; Pellé 2018; Tronto 1993). The emerging "imperative" of responsibility stems from the fact that damages are already tragically present, and that consequences of our actions cannot be circumscribed. This perspective is radically futureoriented and should be implemented according to contextual ways, so as to be able to cover those gray areas where laws or objective principles have proved to be insufficient. The point is not to address the relation between human beings but that to the natural environment that makes human existence possible. In this sense it can be seen as a total effort which must be deployed in every action. As highlighted by Derrida, responsibility exceeds what is known because otherwise it would be the implementation of a technical-cognitivist device, nothing more than the mechanical deployment of a theorem (Derrida 2008; Foddai 2005).

More recent contributions concerning the role of responsibility in science have also recognized the valuable contribution of this existential meaning of the term (Adam \& Groves 2011; Levinas 1998 [1974]; Stilgoe et al. 2013). This stream has sometimes intertwined with virtue ethics, a theoretical framework where an agent is called to develop a character able to make her do, not only what is right, but also what is good (MacIntyre 2007; Pesch 2015; Pettit 2015).

However, it has been noticed that also this last notion, when taken alone, does not resolve the potential infinity of consequences stemming from an action and the impossibility for an individual to take them all in charge (Ricoeur 2000; Spämann 1975). Besides, given the increasingly plural nature of societies, it is debatable what a virtuous behavior might mean. Although they are powerful forces able to permeate the gray areas of human actions, ethics of care and virtue ethics suffer from indeterminacy, which makes them unsuitable for assuming an objective regulatory stance.

If all these different understandings encounter some major limitation, we could be wondering what meaning of responsibility can be appropriate to offer a regulatory role for research and innovation.

Furthermore, as we have seen, it might be argued that it becomes increasingly difficult to distinguish between individual and collective responsibility given that actions and consequences are tangled amongst different actors. I believe that we can find a solution to this problem if we take a look at some previous conceptual attempts to solve this question. 


\section{Robert Gianni}

The theoretical and practical polysemy characterizing the concept of responsibility has been puzzling commentators for a long time. It is difficult to settle the question with regard to the ultimate sense of responsibility. What seems to reconcile the different authors who have analyzed its historical path, though, is that we can find an evolution integrating the constant necessity to guarantee the correct functioning of social relations with the historical changes in agency (Foddai 2005; Genard 1999; Levi-Bruhl 1884; Villey 1977). Responsibility, wrote Lévi-Bruhl in 1884, is a fragile notion owing its multiple senses to the superposition of elements of different periods. Also for Villey, although his understanding differs from that of Lévi-Bruhl, responsibility is the fruit of a secular evolution due to a series of changes and needs for a social, political and juridical character. "Similar to a geological formation," takes up Foddai, the concept of responsibility "reveals in each of its layers the context of ideas and structures of thought in which it has been forged" (Foddai 2005, p. 7).

It has been noticed that there is often a discrepancy between theory and action when it comes to responsibility. What Bradley called a vulgar understanding of responsibility differed, in his view, from the doctrines of the philosophers (Bradley 2018). Arnaldi and Bianchi, following Weber, distinguish a theoretical plan where responsibility is traversed by a theoretical clash, and the practical one, where the two sides are often applied in a hybrid way (Arnaldi \& Gorgoni 2016). Jean-Louis Genard in his reconstruction also concludes that, when it comes to a polysemic concept like responsibility, theory often separates what is conjoined in practical affairs (Genard 1999).

Accordingly, many scholars have suggested the necessity to adopt an integrative and complementary conception of responsibility (Gianni 2016; Grunwald 2018). Foddai believes that an analysis with regard to its historical evolution does not necessarily impede the formulation of a conception of responsibility that enshrines its different meanings (Foddai 2005). Rosanvallon augurs a new foundation of political responsibility on the basis of its two main senses, accountability as well as its role towards future outcomes (Rosanvallon 2015). Sartori also refuses a reduction of political responsibility to the former, endorsing the strong role of the latter for a good democratic practice (Sartori 1987).

Spämann had already suggested that responsibility should be an arbitration between the controllable and foreseeable effects of an action and its unlimited consequences (Spämann 1975). Also Ricoeur, following a Hegelian scheme, calls for a "moral judgment in some specific circumstance" on the basis of an ethics "careful to preserve a distance between imputability, solidarity and shared risks" (Gianni 2018; Ricoeur 2000, pp. 34-35).

What most of the commentators are then concluding is that the uptake of responsibility should be conceived in a complementary and equidistant way because all the meanings of the concept contribute to defining its overall sense.

This integrative and contextual approach appears to be in line with our current models of democracy that see responsibility as a device able to not only protect current societies, but also produce better futures (Dahl 1989; 
Sartori 1987). It is important to highlight this positive and proactive side of responsibility that departs from the solid ground of hard regulations to create better futures. As suggested by Sartori, policy-makers are responsible in a double sense: they are responsible in front of the people of what they have done, but also for what they are going to do.

However, there is still a small passage that is missing, although it is implicit in a holistic, or ethical-political understanding of responsibility.

Responsibility is becoming even more complex with the extension of power that humanity is assuming through technology. However, it has been highlighted that, although the concepts may overlap, power is not identical with freedom (Sartori 1987). The latter can only be exercised, and in a responsible way, through a series of institutional conditions which define their possibilities and appropriateness (Böckenförde 2010; Gianni 2018; Honneth 2014; Seillan 2016).

This argument, which might appear abstract at a first glance, helps us in understanding that an actor cannot be assumed to be responsible if she has not been guaranteed the necessary level of freedom. Without entering the debate about the social pathologies caused by a short-circuit between social pressures about responsibility and actual individual capacities (Ehrenberg 1998), it is worth recognizing that actors, researchers for instance, need to follow a whole set of rules and drivers that frame their investigations. So, if researchers cannot be seen to be fully responsible for their choices, it is because they are entrenched in complex systems, or "orders of recognition" (Ferry 1991) and their freedom to choose what they would consider right cannot be fully exercised (Beck 1992; Gianni 2016; Stilgoe et al. 2013).

In general, I believe it is important to highlight this polyhedric and multilevel nature of the concept of responsibility, which can be implemented in different ways and which offers a high degree of flexibility. At the same time, these implementations are always framed by a discourse and specific institutional measures that render them not only effective but possible. A multi-level but integrative understanding of responsibility can represent an improvement in terms of both efficiency and justice for researchers and innovators. If it is true that actors cannot operate outside a given regulatory framework the stress on care or virtue can still offer a more contextual and subjective way to enforce responsible practices maintaining the process efficient. Without the necessity to overburden scientists or innovators with additional and strong regulations, it is left to them to translate a responsible approach into actions. At the same time, a multi-level conception will be stronger in addressing the level of responsibility demanded from actors and its actual feasibility, avoiding processes of “over-responsibilization.” A risk that we already incur is the continuous and disproportionate appeal to responsible behaviors that create a short-circuit between what an actor is called to do and what she is actually capable of doing (Ehrenberg 1998). In this way the overall objective and importance of responsible practices become at best unbearable.

Therefore, we have assumed that responsibility is an integrative, multidimensional and contextual regulator of different perspectives, called to be 


\section{Robert Gianni}

responsive to the challenges of our societies (Pellizzoni 2004). We now need to evaluate to what extent current institutional mechanisms of RRI enable such an understanding.

\subsection{Six keys and their relevance for science and democracy}

In this part I will propose a reading of the criteria adopted by the EC to develop responsible practices of research and innovation, more specifically of the six keys.

The reasons to choose the EC's keys are mainly twofold. The first one is that the six keys represent the methodological tools adopted by the main public funding institution in Europe, and therefore inevitably affect the framing of research and innovation. It could be argued that RRI has also been developed according to different criteria (Owen et al. 2013). However, the preference assigned to the keys does not exclude the adoption of "actions" in those thematic areas. Klassen et al. have encouraged such an integration between the academic debate and policy-oriented measures (Klassen et al. 2018). Besides, as has been pointed out by Stilgoe et al., research and innovation have to go through a whole series of steps before they can actually be introduced in society (Stilgoe et al. 2013). Similarly, responsibility requires institutional measures in order to be realistically enacted. Therefore, institutional measures are always necessary for their implementation.

As recently stated by the Commissioner Carlos Moedas quoting Jean Monnet, nothing is possible without the citizens and nothing is sustainable without the institutions. ${ }^{9}$

The second reason lies in the fact that, despite a surrounding skepticism about the future of RRI, the keys will most probably continue to play a role in the ethical development of research and innovation.

If we accept this methodological aspect we can agree that it is more efficient to work or assess the existing institutional measures because they appear effective and they are not necessarily limited to the acronym of RRI.

When RRI was adopted by the EC, former Commissioner GeorgheanQuinn provided the research community with six main thematic areas through which RRI could and should be implemented. Engagement, gender, open access, science education, ethics and governance are the key references to follow, in order to assess a responsible approach to research and innovation.

\subsubsection{Engagement}

Engagement is defined by the EC as:

Engagement of all societal actors - researchers, industry, policy -makers and civil society - and their joint participation in the research and 
innovation process, in accordance with the value of inclusiveness, as reflected in the Charter of Fundamental Rights of the European Union.

(EC 2012)

Being responsible then entails that:

the societal challenges are framed on the basis of widely representative social, economic and ethical concerns and common principles. Moreover, mutual learning and agreed practices are needed to develop joint solutions to societal problems and opportunities, and to pre-empt possible public value failures of future innovation.

(EC 2012)

This definition encourages an integrative framework of the different perspectives in society and it addresses the problem of framing by opening to the variety of interests at stake. It relies on common measures and fosters deliberative processes. Furthermore, the explicit reference to the Charter of Fundamental Rights of the European Union provides a thin, although important, normative reference to the debate on which RRI can rest. In this regard, it appears to be implementing a notion of responsibility that is wide, inclusive and contextually flexible. Furthermore, participatory practices are the main tools suggested to increase both scientific investigations and democratic processes. It is important though that engagement is conceived in a meaningful way, overcoming the risks of power imbalance and windowdressing (Fung 2006). Therefore, the basic presupposition for the translation of responsible approaches needs to complemented by further specifications.

\subsubsection{Gender}

Gender can be seen as a first additional specification of engagement, defining not only the necessity to establish a dialogue, but also delineating basic ways of avoiding discriminations amongst participants. The EC believes that it is crucial to address inequality in the representation of women and men in different processes. Gender aspects should not only target a quantitative increase of female representation, but also a deeper sensibility to the contents of research and innovation. Gender is meant to represent a dimension where actors can reflect on the biases based on biological assumptions that affect scientific research and its products.

The different quantitative and qualitative aspects of gender are difficult to disentangle. It might be argued that quantitative satisfaction of gender aspects in one process could also decrease the necessity to deepen the discussion about its qualitative integration. Gender discussion could limit its scope on particular aspects, overlooking the preconditions that enact general forms of discrimination as economic assets, political power and cultural 
authority (Connell, 2005). Or, to paraphrase Haraway, science should not ignore the plurality of the world's interpretations (Haraway 1991).

However, quantitative evidence of social discrimination can trigger a discussion about its reasons and actions of implementation (Wojniak 2017). If it is true that "the under-representation of women continues to characterize participation in science \& technology" (EC 2016), this fact can be a strong motivation for change. Tangible, measurable products of science, either technologies or articles, ${ }^{10}$ can represent an entry stage for climbing back up the technology ladder to its paradigm stage (Bessant 2013).

Gender entails a double role within the framework of RRI. On the one hand, it defines the necessity to be inclusive, while on the other hand it suggests that a quantitative opening of the process must be accompanied by qualitative aspects. It appears to be strongly valuable for science and democracy. This key in fact can support scientific investigation by providing knowledge about gender differences and needs. It can also increase democratic legitimacy by overcoming forms of discrimination and enhancing equal participation.

\subsubsection{Open access}

Open access can be seen as complementary to science education. In order to increase the level of knowledge, researchers, innovators and policy-makers should commit to providing access to the results of their research. Sharing does not only increase the overall level of knowledge but also favors a more transparent management of research and innovation funding.

Open access is one of the two areas that are meant to support the active and passive participation of a broad range of actors in the development of scientific processes. The EC officially conceives it as "giving free online access to the results of publicly-funded research" (EC 2012), but its extension can be widened according to the specific context. It can be agreed that an easier access to sources of information can favor knowledge building, which is crucial to support a conscious and just decision. In fact, it is not difficult to conceive the features of open access as those of transparency, a quest that has become stronger than ever, and that represent a cornerstone of contemporary democracies (Hollyer et al. 2011; Shapiro 2012). ${ }^{11}$ Science can benefit from the increase of openness if it is conceived also at the political level, defining the choices and the trajectory that scientists are called to make and the institutional conditions they need to deal with. It strengthens the democratic process by the necessary degree of justification that transparent decisions are required to provide at different stages of the process (Weil et al. 2013).

\subsubsection{Science education}

Science education aims at increasing the amount of knowledge as well as its quality. Through means of education, the objective is to make society able 
to understand science and "fully participate and take responsibility in the research and innovation process."

Science education is a crucial step if we want to complete the passage between information and knowledge. As stated by Sartori,

knowledge implies a mental control over the information that is in no way supplied by the information itself. Given an equal amount of information, a person may either be competent or remain incompetent, depending on whether she perceives correctly which means are appropriate to what ends, and thereby which consequences derive from which decisions or action.

(Sartori 1987, p. 117)

Deficit of understanding is for the public a critical aspect, undermining the possibility of responsible practices (Gianni 2018; Wynne et al. 2007). As clearly highlighted by juridical responsibility, the basic prerequisite for accountability and liability is the epistemic capacity of understanding external inputs (Hart 2008).

The information acquired through open access should then be preceded and integrated by an education to understand and to filter information in order to transform it into knowledge. Therefore, we can conceive this not only as education of future generations, but also as the overall capacity building that any participation process should foresee if eager to integrate competent opinions into its debate (Kitcher 2011). This key is the enabler of an emancipatory process in the wake of our current models of deliberative democracies. Rendering a larger range of the population able to understand scientific data can also help overcome fears and mistrust about science, and can offer a relevant source of additional information for researchers.

\subsubsection{Ethics}

Ethics stands for the necessity of doing the right thinking in the research and innovation process. The EC clearly highlights that ethical thinking should not be reduced to existing mandatory legal aspects but should be implemented by respecting fundamental rights and highest ethical standards. The clear normative reference to the Charter of Fundamental Rights expresses the objective of gaining "acceptability" through societal relevance.

However, in order to be consistent with the analyses of the other five keys, it would be more sensible to consider a more complex $t$ version of this term. Although ethics is one of those controversial terms the meaning of which can be very broad (Reber 2016), the EC's definition of ethics, and its relation with the other keys, seems to reflect a pragmatist interpretation of the term. Accordingly, ethics, rather than being a set of predefined rules impeding progress, is the integration of objective rights and subjective values 
into a common and contextual framework (Adorno 1993, 2005; Dewey 1991; Gianni 2018; Ritter 1982).

Following this line, ethical processes aim at overcoming unilateral or unjustified perspectives by considering social interactions in a holistic way. This fifth key concerns the analysis and integration of different values and norms into the design and development of research and innovation. This interpretation matches the abovementioned understanding of responsibility that integrates the different levels of regulatory aspects. Ethics requires that different cultural values and interests are taken to the fore according to different levels of regulations. It offers a multi-level, refined tool to improve pluralism in democratic societies. In this sense it is reasonable to conceive it as a pragmatist approach that distances itself from both applied ethics and traditional philosophy by embracing a dynamic perspective (Keulartz et al. 2004).

\subsubsection{Governance}

The description of the last key, governance, is particularly relevant for the purpose of our analysis and for understanding the sense of the keys. "Policy-makers also have a responsibility to prevent harmful or unethical developments in research and innovation" (https://ec.europa.eu/research/ swafs/pdf/pub_rri/KI0214595ENC.pdf).

Governance in fact should be conceived as an umbrella term expressing the necessity that policy-makers develop models of RRI that integrate all other keys.

According to Jessop, governance is an "important mean to overcome the division between rulers and the ruled in representative regimes, and to secure the input and commitment of an increasingly wide range of stakeholders in policy formulation and implementation" (Jessop 2002, p. 3). According to this definition and to the delineation made by the EC, governance within the RRI framework seems to be responding to these objectives. Governance is considered to be more efficient because it crosscuts different social dimensions and can be implemented in a faster way with respect to government (Kuhlmann \& Ordonez-Matamoros 2017). Lee and Petts suggest that governance in the RRI framework should also be conceived according to the upscale of science policies, becoming a multi-level process and thus developing a set of soft-law instruments besides the hard-law ones (Goos \& Lindner forthcoming; Lee \& Petts 2013).

The focus on soft regulations which RRI seems to encourage can be considered a weakening factor because it relies on the willingness of actors to commit, implying a concrete level of arbitrariness, which can undermine its regulatory force (Wickson \& Forsberg 2015). At the same time, such openness can represent a potential strength because of the capacity to be adapted to different contexts by a larger number of actors (Gorgoni 2018).

Although some of the "tools" entailed in the governance of RRI might not represent a novelty (Zwart et al. 2014), the way in which they are combined 
represents an original and more refined attempt to offer a multi-level and contextual regulatory framework (Fisher \& Rip 2013; Gianni \& Goujon 2018; Goos \& Lindner forthcoming; Grunwald 2011, 2016, 2018).

Governance, within this framework, is characterized by the importance allocated to a broader assessment of implementation and societal impact; a more proactive attitude towards inclusiveness and competition; and an accentuated responsiveness to the future, which opens up space for a debate about the goals of research and innovation.

All these aspects are clearly detectable by the adoption of an ethical understanding of responsibility (fifth key), which implies a more democratic and proactive understanding of technical processes.

\subsection{The implementation role of the six keys for science and democracy}

After having operated an analysis of the EC's six keys which enables us to implement them at different levels, it is important to go a step further and to highlight two additional aspects about their operationalization.

The first aspect concerns the keys taken singularly. Although we have proposed an interpretation of each key based on an ideal understanding, this perspective is not blind to the criticisms that each of them might be incurring.

Commentators have highlighted two main issues. The first one concerns the potential window-dressing function they could play, and the second one focuses on the difficulty implementing certain keys in specific research fields. For instance, some authors have highlighted the risk for engagement to be instrumentalized in different manners (Callon et al. 2009; Fung 2006; Honneth 1991; Stilgoe et al. 2013). Also other keys like gender might raise some issues with regard to the relation between a thin (quantitative) and thick (qualitative) integration of the concept (Connell 2005). Open access understood as transparency has been questioned as it might clash with the necessary levels of confidentiality (Blok 2018; Blok \& Lemmens 2015).

Although these criticisms sound legitimate, I believe there are two more aspects that we need to consider to help us overcome these limitations. The first one is that these shortcomings do not always apply, and therefore we should not be dismissing the keys a priori. Several aspects of research are or should be public, especially their outcomes, and should go under scrutiny in order to improve them. Besides, the fact that key concepts encounter several barriers should not be a reason to dismiss them, but rather a motivation to seek for appropriate or alternative forms of implementation.

Several authors have also suggested that, when implementation does not appear evident or easy, it might be sensible to shift up the reflection to a meta-level (Stahl et al. 2013; Van den Hoven et al. 2012) or to a second order (Gianni \& Goujon 2018; Maesschalck 2017) in order to question the framing that drives the overall scientific process. A meta-level reflection 
can help in addressing the apparent clash between normative drivers and the practical obstacles pertaining to a specific field because it suggests a reflection on the broader meaning of a normative concept, so to find alternative ways to promote its uptake. For instance, open access can also be conceived as a form of transparency not on the methodology or on specific data, but on the objectives that a certain methodology should produce. In fields where gender ratio might be seen as achieved, other forms of genderbiased mechanisms or product might be scrutinized. In other words, it is more sensible to understand the keys not as indications to perform a clear and specific assessment, like a box-ticking exercise, but rather as overall dimensions, the meaning of which needs to be explored in order to improve the ethical stance of a research process.

A second-order reflexivity is meant instead to protect normative objectives from instrumentalization. If engagement, for instance, can be criticized because it appears not effective in many cases, this weakness should not always be identified with the principle as such, but with the ways in which is implemented. In this sense, a second-order reflexivity can deepen the knowledge about the overall process so as to unveil potential gaps between supposed objectives and actual working mechanisms. By questioning the framework, practitioners can better understand the main objectives at the heart of the keys, assess an objective with the measures put in place, and eventually question the mismatch between the two aspects without the necessity for getting rid of the concept as such.

An example of implementation of the six keys taken singularly has been carried out in a recent EC research project, BODEGA, dealing with human factors and their development after the introduction of automatization in border controls. The project conducted field studies in different border check-points observing the usual procedures put in place to check passenger flows entering and exiting the Schengen area. By applying the six keys, the project was able to provide a whole set of recommendations for improving the border control process without leaking sensitive information or undermining security needs. One example concerns uniforms for border guards which are designed for men and can become ineffective or disturbing when used by a woman. As clothing and uniforms might have been designed before women were entitled to enter police corps, this suggests that what is missing are simply broader participatory structures that can bring to the attention some diverse issues. What has also emerged is that the taboo surrounding certain research fields or practitioners is often detrimental because it prevents a broader analysis that would not undermine their main scope. ${ }^{12}$

The second aspect about their operationalization focuses on the relation between the keys. An approach that I believe has not been discussed extensively but that I think is indeed part of the EC's intentions is to conceive the keys in a relation of complementarity. ${ }^{13}$ Such coupling, that we could also interpret in a lexical way, can be justified by a factor that it's not directly linked to the fact that they are part of one strategic document. 
The keys in fact entail a logic and practical complementarity in the framework of a deliberative democracy. It is difficult to think of a sincere participatory process that prescinds from the appropriate competences. Also, an open discussion about the future that neglects gender aspects might raise some perplexity. The examples could be several, but what they suggest is that each key is necessary in order to produce a responsible approach which can be inclusive not only of different actors, but also of underrepresented issues. This is corroborated by the fact that the keys tend to merge an epistemic stance with a value-based one, answering the challenges of postnormal science (Funtowicz \& Ravetz 1993). It might be correctly argued that the absence of one of the keys from an analysis does not necessarily produce irresponsible approaches. However, I believe that there would be a great difference in terms of a democratic approach if one of the keys were completely dismissed.

Despite the possible and reasonable objections that this holistic approach could raise, I believe that this hypothesis could represent a fruitful attempt in the cross-fertilization process between science and democracy. Besides, although the keys and the underlying understanding of better futures have also been questioned (De Saille \& Medvecky 2016), I believe it would be more fruitful to improve the general understanding of RRI through mechanisms that are in place and that are meant to favor such criticisms. It is most probably through an increment of engaging practices based on aware and ethical stances that we might hope to refine the understanding of RRI.

The ideal character and the challenges of this perspective should not, in my opinion, discourage experimentation. RRI and democracy both being soft-regulatory frameworks covering different fields, they will always suffer from the distance between ideal features and their actual implementation, but this does not imply that we should not try to fill this gap. As Dewey has repeatedly suggested, democracy should not be reduced to a fixed political model but rather understood as a method to be applied in all social interactions (Dewey 1991).

To summarize, the six keys proposed by the EC are instrumental to creating participatory processes in which a wide range of actors can interact to deliberate about intended futures while considering diverse values and interests. This perspective is supported by a multi-level understanding of responsibility and by the democratic principles embedded in the keys. The conception of democracy they enact is one where subjects should be put in the situation to self-determine their ends on the basis of moral and epistemic pluralism.

At this point of our analysis where we have adopted a reference model of RRI, let us briefly recap the evaluation of its scientific and democratic relevance.

Considering scientific relevance, we can recall how this six-key-based RRI framework integrates an epistemic moment (technical knowledge) with the inclusion of actors carrying different interests, values and information 


\section{Robert Gianni}

(pluralism). It appears that scientific accuracy can but benefit from such broadening of perspectives. The criticism directed at the appropriateness of some keys for an efficient research and innovation process has also proven to be misdirected. The argument that certain drivers like transparency and openness cannot be fully implemented in research (Blok \& Lemmens 2015) can in fact be overcome if we accept that these and other normative tools, when implemented, can be used at different levels (Gianni \& Goujon 2018).

If we believe in the necessity and advantages of an opening of scientific research objectives, we can then judge RRI and its keys as a useful methodological tool to improve this process. The keys as a responsible approach to research and innovation support the engagement of a wider range of conscious actors' interests and values into the delineation of futures. Furthermore, they include the necessary measures to implement effectively and rightly such exchange between scientists and citizens. When correctly and robustly implemented, RRI can represent an effective tool to help science progress in its social contribution by integrating social values and interests into its trajectory.

Therefore, following this perspective, it is plausible to deduce that RRI is in principle of high relevance to the development of scientific investigation.

On the basis of the conception of a dynamic, active and deliberative model of democracy, like the one proposed by Dewey, it is not difficult to see how RRI can be judged in line with it and is thus relevant. RRI tries to bring democratic practices into science by introducing some basic tools through which citizens can express their views in an equal and free manner. Furthermore, RRI aims to reduce inequalities by empowering citizens to actively participate in technology trajectories. The possibility of developing a reflexive deliberation about ethical aspects and debate on additional measures to be integrated to technical processes appears nowadays not only as a managerial opportunity but also as a democratic necessity.

I do not think that it is misleading to suggest that the keys are tools that innovatively try to put citizens in the position to exert their "humanity," i.e. to enter the discourse about science trajectory through means of equality and freedom steered by solidarity. By integrating an epistemic dimension with a value-based one, RRI is an attempt to implement a participatory democratic model in science - one that enables citizens to express their values and preferences about objectives in a reasonable and competent way. Therefore, it implies an understanding of research and innovation as fields that should be subjected to the principles of democracy. This appears in line with the radicalization of democracy promoted by pragmatists (Dewey 1991).

It avoids the risk of a purely expert-based approach without losing the reasonable ground on which to initiate a dialogue. It offers an institutional, democratic and thus balanced structure in which actors are called to interact and imagine their horizons. It does so by recognizing and respecting the plurality of perspectives at stake. RRI acknowledges plurality as a challenge and aims to generate futures that are the conscious fruits of this diversity. 
As stated by Galli, if even democracy does not have a center any more, it is not possible that it does not have an end (Galli 2011).

\subsection{Conclusions}

We have analyzed the main features and challenges of scientific and democratic processes to understand what could be relevant for their respective futures. We have understood that they share the need to integrate broader perspectives into their decision-making process. At the same time, the chapter tried to highlight that the quest for a democratization of science should not be seen as an intrusion on scientific rigor but rather as a mutual deliberation about the objectives of science. I have then highlighted that RRI is an operational framework, with the EC's six keys functioning as regulatory criteria in order to increase the cross-fertilization between science and democracy. According to this perspective RRI appears highly relevant from a scientific and democratic point of view because it entails a series of tools that actualize the necessity of enabling citizens and scientists to communicate with each other.

However, this does not mean that RRI is necessarily going to keep its promises if the different actors are not going to commonly implement these indications. It is useful to remember that one of the main significances of the original concept of responsibility under Roman law was exactly the one of guaranteeing consistency between promises and facts (Benveniste 1969). Only if its features will be implemented in an institutionally substantive way will we avoid mistrust and disaffect about responsibility, and will we be able to shorten the gap between science and society.

\section{Acknowledgments}

This research was supported by the Province of Limburg, The Netherlands, under grant number SAS-2019-00061, and by the European Commission under grant number 741402 .

\section{Notes}

1 I will talk here of science in general, although the focus is on research and innovation which are often different in their scope. The differences and overlaps will emerge in the tendency to increase the contextual response of science in general.

2 The popularity of the butterfly effect is witnessed by the enormous number of different contributions in different divulgation sectors.

3 For an interesting project about this, see: www.sienna-project.eu

4 Burget et al. reviewed 235 articles mentioning RRI, but they could not include larger contributions and deliverable projects, which would increase this number substantially.

5 For an analysis at the policy level, see NewHoRRIzon project, D.4.1, https:// newhorrizon.eu/wp-content/uploads/2019/03/D-4.1-Diagnosis-RRI-in-SocietalChallenges-1.pdf 
6 https://epsrc.ukri.org/index.cfm/research/framework/

7 https://ec.europa.eu/research/swafs/pdf/pub_public_engagement/responsibleresearch-and-innovation-leaflet_en.pdf

8 https://newhorrizon.eu https://ec.europa.eu/research/evaluations/index.cfm?.pg= h2020evaluation

9 https://ec.europa.eu/commission/commissioners/2014-2019/moedas/ announcements/ep-high-level-conference-eu-research-and-innovation-our-daily-life_en

10 According to the SHE Figures report:

"In the period spanning from 2010 to 2013, the propensity to integrate a gender dimension in research content measured in scientific articles in the EU-28 ranged from virtually zero in agricultural sciences, engineering and technology, and natural sciences to over $6 \%$ in the social sciences"

(EC 2016).

11 See also http://www.oecd.org/about/secretary-general/opennessandtransparencypillarsfordemocracytrustandprogress.htm

12 The remarkable results obtained suggest that it is an optimistic path to explore: https://bodega-project.eu

13 For a general discussion about the keys, see Spaapen et al. (2015).

\section{References}

Abbagnano, N. (1957). Il giudizio di responsabilità nella morale e nel diritto. Rivista di Filosofia, 1, pp. 30-45.

Adam, B. and Groves, C. (2011). Futures tended: care and future-oriented responsibility. Bulletin of Science, Technology and Society, 31(1), pp. 17-27.

Adorno, T. W. (1993 [1963]). Hegel: Three Studies. Cambridge, MA: MIT Press.

Adorno, T. W. (2005 [1951]). Minima Moralia: Reflections on Damaged Life. London: Verso.

Arnaldi, S. and Bianchi, L. (2016). Responsibility in Science and Technology. Wiesbaden: Springer.

Arnaldi, S. and Gorgoni, G. (2016). Turning the tide or surfing the wave? Responsible Research and Innovation, fundamental rights and neoliberal virtues. Life Sciences, Society and Policy, 12(6), pp. 1-19.

Audard, C. (2009). Qu'est-ce que le Libéralisme? Éthique, Politique, Société. Paris: Gallimard.

Beck, U. (1992). Risk Society: Towards a New Modernity. London: Sage Publications.

Benveniste, E. (1969). Le Vocabulaire des Institutions Indo-Européennes. Paris: Les Éditions de Minuit.

Berlin, I. (2002 [1969]). Liberty: Incorporating Four Essays on Liberty. Oxford: Oxford University Press.

Bessant, J. (2013). Innovation in the Twenty-First Century. In: R. Owen, J. Bessant and M. Heintz (eds.), Responsible Innovation. Managing the Responsible Emergence of Science and Innovation in Society. Hoboken, NJ: John Wiley, pp. 1-25.

Bijker, W. E., Hughes, T. P. and Pinch, T. J. (eds.), (1987). The Social Construction of Technological Systems: New Directions in the Sociology and History of Technology. Cambridge, MA: MIT Press.

Blok, V. and Lemmens, P. (2015). The Emerging Concept of Responsible Innovation. Three Reasons Why It Is Questionable and Calls for a Radical Transformation of the Concept of Innovation. In: B.-J. Koops, J., Oosterlaken, I. Romijn, et al. (eds.), 
Responsible Innovation 2: Concepts, Approaches, and Applications. Dordrecht: Springer, pp. 19-35.

Blok, V., Lubberink, R., van den Belt, H., Ritzer, S., van der Kruk, H. and G. Danen (2018). Challenging the ideal of transparency as a process and as an output variable of Responsible Innovation. The case of 'The Circle'. In: R. Gianni, J. Pearson, J. Reber. (eds.), Responsible Research and Innovation. From Concept to Practices. Oxford: Routledge, pp. 225-244.

Böckenförde, E. W. (2010). Diritto e Secolarizzazione. Dallo Stato Moderno all'Europa Unita. Rome: Laterza.

Bohman, J. and Regh, W. (eds.), (1997). Deliberative Democracy. Cambridge, MA: MIT Press.

Bourgeois, B. (2017). Sept Questions Politique du Jour. Paris: Vrin.

Bradley, F. H. (2018). Ethical Studies. London: Forgotten Books.

Bridgman, P. (1927). The Logic of Modern Physics. New York: MacMillan.

Bucchi, M. and Neresini, F. (2008). Science and Public Participation. In: E. Hackett, O. Amsterdamska and M. Linch (eds.), Handbook of Science and Technology Studies. Cambridge, MA: MIT Press, pp. 449-473.

Burget, M., Bardone, E. and Pedaste, M. (2017). Definitions and conceptual dimensions of responsible research and innovation: a literature review. Science and Engineering Ethics, 23(1), pp. 1-19.

Callon, M., Lascoumes, P., Barthe, Y. (2009). Acting in an Uncertain World: An Essay on Technical Democracy. Cambridge, MA: MIT Press.

Carrabregu, G. (2016). Habermas on solidarity: an immanent critique. Costellations, 23(4), pp. 507-522.

Connell, R. W. (2005), Change among the gatekeepers: men, masculinities, and gender equality in the global arena. Signs, 30(3), pp. 1801-1825.

Dahl, R. A. (1989). Democracy and Its Critics. New Haven, CT: Yale University Press. Derrida, J. (2008). The Gift of the Death. Chicago, IL: Chicago University Press.

De Saille, S. and Medvecky, F. (2016). Innovation for a steady state: a case for responsible stagnation, Economy and Society, 45(1), pp. 1-23.

Dewey, J. (1991 [1927]). The Public and Its Problems. Athens, OH: Swallow Press / Ohio University Press.

Dews, P. (ed.), (1992). Autonomy and Solidarity. Interviews with Jürgen Habermas. London: Verso.

Ehrenberg, A. (1998). The Fatigue of Being Oneself: Depression and Society. Paris: Odile Jacob.

Engle, L. (1993). Vers une nouvelle approche de la responsabilité: le droit français face à la dérive américaine. Esprit, 192(6), pp. 5-31.

European Commission (2012). Responsible Research and Innovation. Europe's Ability to Respond to Societal Challenges. Directorate-General for Research and Innovation, Brussels. Available at: https://ec.europa.eu/research/swafs/pdf/pub_ public_engagement/responsible-research-and-innovation-leaflet_en.pdf

European Commission (2016). She Figures 2015. Directorate-General for Research and Innovation, Brussels. Available at: https://ec.europa.eu/research/swafs/pdf/ pub_gender_equality/she_figures_2015-final.pdf

Ewald, F. (1986). L'Etat Providence. Paris: Grasset et Fasquelle.

Fagotto, E. and Fung, A. (2006). Empowered participation in minneapolis: the neighborhood revitalization program. International Journal of Urban and Regional Research, 30(3), pp. 638-655. 
Ferry, J. M. (1991). Les Puissances de l'Experiénce. Paris: Cerf.

Fisher, E. and Rip, A. (2013). Responsible Innovation: Multi-Level Dynamics and Soft Intervention Practices. In: R. Owen, J. Bessant, and M. Heintz (eds.), Responsible Innovation. Managing the Responsible Emergence of Science and Innovation in Society. Hoboken, NJ: John Wiley, pp. 165-184.

Fishkin, J. and Laslett, P. (eds.), (2003). Debating Deliberative Democracy. London: Blackwell.

Flipse, S. M. (2012). Enhancing Socially Responsible Innovation in Industry. Practical Use for Considerations of Social and Ethical Aspects in Industrial Life Science and Technology. Delft University. Available at: https://pdfs.semanticscholar.org/ 9979/9d2d7e436ccd7d7fa0b595ae106515f4cf3c.pdf.

Foddai, M. A. (2005). Sulle Tracce della Responsabilità. Idee e Norme dell'Agire Responsabile. Turin: Giappichelli Editore.

Fung, A. (2006). Varieties of participation in complex governance. Public Administration Review, 66(1), pp. 66-75.

Funtowicz, S. O. and Ravetz J. R. (1993). Science for the post-normal age. Futures, 25(7), pp. 739-755.

Funtowicz, S. O., Ravetz, J. R. (2008). Beyond complex systems: emergent complexity and social solidarity. In: D. Waltner-Toews, J. J. Kay and N-M. Lister (eds.), The Ecosystem Approach: Complexity, Uncertainty, and Managing for Sustainability. New York: Columbia University Press, pp. 309-322.

Galli, C. (2011). Il Disagio della Democrazia. Turin: Einaudi.

Genard, J.-L. (1999). Grammaire de la Responsabilité. Paris: CERF.

Gianni, R. (2016). Freedom and Responsibility. The Ethical Realm of RRI. London: ISTE/Wiley.

Gianni, R. (2018). The Discourse of Responsibility. A Social Perspective. In: R. Gianni, J. Pearson and J. Reber (eds.), Responsible Research and Innovation. From Concept to Practices. Oxford: Routledge, pp. 11-34.

Gianni, R. and Goujon, P. (2018). What are the Conditions for the Ethical Implementation of RRI? Responsible Governance and Second-Order Reflexivity. In: R. Gianni, J. Pearson and J. Reber (eds.), Responsible Research and Innovation. From Concept to Practices. Oxford: Routledge, pp. 172-207.

Godin, B. (2015). Innovation Contested - The Idea of Innovation over the Centuries. London: Routledge.

Goffman, E. (1974). Frame Analysis: An Essay on the Organization of Experience. New York: Harper and Row.

Goodin, R. (2012). Innovating Democracy. Democratic Theory and Practice After the Deliberative Turn. Oxford: Oxford University Press.

Goos, K. and Lindner, R. (Forthcoming). Genealogies of the concept of RRI - from fragmented notions towards commonalities and disparities. To be published.

Gorgoni, G. (2018). Responsible Research and Innovation and the governance of human enhancement. Nano Ethics, 12(3), pp. 257-267.

Gottweis, H. (2008). Participation and the new governance of life. BioSocieties, 3(3), pp. 265-286.

Grinbaum, A. and Groves, C. (2013). What is 'Responsible' about Responsible Innovation? Understanding the Ethical Issues. In: R. Owen, J. Bessant and M. Heintz (eds.), Responsible Innovation. Managing the Responsible Emergence of Science and Innovation in Society. Hoboken, NJ: John Wiley, pp. 119-142. 
Grunwald, A. (2011). Responsible innovation: bringing together technology assessment, applied ethics, and STS research. Enterprise and Work Innovation Studies, 7(IET), pp. 9-31.

Grunwald, A. (2016). The Hermeneutic Side of Responsible Research and Innovation. London: ISTE/Wiley.

Grunwald, A. (2018). Responsibility Beyond Consequentialism. The EEE Approach to Responsibility in the Face of Epistemic Constraints. In: R. Gianni, J. Pearson and J. Reber (eds.), Responsible Research and Innovation. From Concept to Practices. Oxford: Routledge, pp. 35-49.

Guston, D. H. (2001). Integrity, responsibility, and democracy in science. SciPolicy. A Journal of Science and Health Policy, 1(2), pp. 168-189.

Hajer, M. and Wagenaar, H. (eds.), (2003).Deliberative Policy Analysis. Understanding Governance in the Network Society. New York: Cambridge University Press.

Haraway, D. (1991). A Cyborg Manifesto. New York: Routledge.

Hart, H. L. A. (2008 [1968]). Punishment and Responsibility. Essays in the Philosophy of Law. Oxford: Oxford University Press.

Hegel, G. W. F. (1991 [1821]). Elements of the Philosophy of Right. Cambridge: Cambridge University Press.

Holden, B. (ed.), (1999). Global Democracy. Key Debates. Oxford: Routledge.

Hollyer, J. R., Rosendorff, B. P. and Vreeland, J. R. (2011). Democracy and transparency. The Journal of Politics, 73(4), pp. 1191-1205.

Honneth, A. (1991). The Critique of Power: Reflective Stages in a Critical Social Theory. Cambridge, MA: MIT Press.

Honneth, A. (2014). Freedom's Right. The Social Foundations of Democratic Life. Cambridge: Polity Press.

Horkheimer, M. and Adorno, T. W. (2002 [1947]). Dialectic of Enlightenment. Stanford, CA: Stanford University Press.

Jacquet, V. (2018). The role and the future of deliberative mini-publics: a citizen perspective. Political Studies, 67(3), pp. 639-657.

Jasanoff, S. (2004). States of Knowledge. The Co-production of Science and Social Order. London: Routledge.

Jasanoff, S. (2016). The Ethics of Invention. Technology and the Human Future. New York: Norton.

Jessop, B. (2002). Governance and Metagovernance: On Reflexivity, Requisite Variety, and Requisite Irony. Available at: www.lancaster.ac.uk/fass/resources/sociologyonline-papers/papers/jessop-governance-and-metagovernance.pdf

Jonas, H. (1984). The Imperative of Responsibility: In Search of Ethics for the Technological Age. Chicago, IL: University of Chicago Press.

Kant, I. (1997 [1788]). Critique of Practical Reason. Cambridge: Cambridge University Press.

Kelsen, H. (2005 [1934]). Pure Theory of Law. Berkeley, CA: California University Press.

Keulartz, J., Schermer, M., Korthals, M. and Swierstra, T. (2004). Ethics in technological culture: a programmatic proposal for a pragmatist approach. Science, Technology, \& Human Values, 29(1), pp. 3-29.

Kitcher, P. (2011). Science in a Democratic Society. New York: Prometheus Books.

Klassen, P., Rijnen, M., Vermulen, S., Kupper, F. and Broerse, J. (2018). Technocracy vs Experimental Learning in RRI. On Making the Most of RRI's Interpretative 
Flexibility. In: R. Gianni, J. Pearson and J. Reber (eds.), Responsible Research and Innovation. From Concept to Practices. Oxford: Routledge, pp. 77-98.

Krishna, V. (2013). Changing Social Relations between Science and Society: Contemporary Challenges. Available at: https://halshs.archives-ouvertes.fr/ halshs-00910707/document

Kuhlmann, S. and Ordonez-Matamoros, G. (eds.), (2017). Research Handbook on Innovation Governance for Emerging Economies. Towards Better Models. Cheltenham: Edward Elgar.

Lee, R. G. and Petts, J. (2013). Adaptive Governance for Responsible Innovation. In: R. Owen, J. Bessant and M. Heintz (eds.), Responsible Innovation. Managing the Responsible Emergence of Science and Innovation in Society. Hoboken, NJ: John Wiley, pp. 143-164.

Lévi-Bruhl, L. (1884). L'Idée de la Responsabilité. Paris: Bourloton. Available at: https://archive.org/details/lidederesponsab00lvgoog/page/n15

Levinas, E. (1998 [1974]). Otherwise Than Being or Beyond Essence. Pittsburgh, PA: Duquesne University Press.

Limoges, C. (1993). Expert knowledge and decision-making in controversy contexts. Public Understanding of Science, 2(4), pp. 417-442.

Lorenz, E. (1963). Deterministic non-periodic flow. Journal of the Atmospheric Sciences, 20, pp. 131-141. Available at: https://journals.ametsoc.org/doi/pdf/ 10.1175/1520-0469\%281963\%29020\%3C0130\%3ADNF\%3E2.0.CO\%3B2

MacIntyre, A. (2007). After Virtue: A Study in Moral Theory. Notre Dame, IN: Notre Dame University Press.

Maesschalck, M. (2017). Reflexive Governance for Research and Innovative Knowledge. London: ISTE/Wiley.

Manin, B. (2012). Principes du Gouvernement Représentatif. Paris: Flammarion.

Mazzuccato, M. (2015). The Entrepreneurial State. Debunking Public vs Private Sector Myths. New York: Public Affairs.

McKeon, R. (1957). The development and significance of the concept of responsibility. Revue Internationale de Philosophie, 1, pp. 3-32.

Moore, M. S. (1984). Law and Psychiatry. Rethinking the Relationship. Cambridge: Cambridge University Press.

Nowotny, H. (2015). The Cunning of Uncertainty. Oxford: Polity.

Owen, R., Bessant, J. and Heintz, M. (eds.), (2013). Responsible Innovation. Managing the Responsible Emergence of Science and Innovation in Society. Hoboken, NJ: John Wiley.

Pansera, M. and Owen, R. (2018). Innovation and Development: The Politics at the Bottom of the Pyramid. London: ISTE/Wiley.

Paulson, L. S. (1992). The neo-Kantian dimension of Kelsen's Pure Theory of Law. Oxford Legal Studies, 12(3), pp. 311-332.

Pavie, X. (2018). From Responsible-Innovation to Innovation-Care. Beyond Constraints, a Holistic Approach of Innovation. In: R. Gianni, J. Pearson and J. Reber (eds.), Responsible Research and Innovation. From Concept to Practices. Oxford: Routledge, pp. 245-267.

Pavie, X., Scholten, V. and Carthy, D. (2014). Responsible Innovation. From Concept to Practice. Singapore: World Scientific.

Pearson, J. (2018). Ever Deeper Research and Innovation Governance? Assessing the Uptake of RRI in Member States' Research and Innovation Programmes. 
In: R. Gianni, J. Pearson and J. Reber (eds.), Responsible Research and Innovation. From Concept to Practices. Oxford: Routledge, pp. 99-128.

Pellé, S. (2018). Responsibility in Research and Innovation. The Potential of Care Ethics. In: R. Gianni, J. Pearson and J. Reber (eds.), Responsible Research and Innovation. From Concept to Practices. Oxford: Routledge, pp. 268-285.

Pellé, S. and Reber, B. (2015). Responsible Innovation in the light of moral responsibility. Journal on Chain and Network Science, 15(2), pp. 107-117.

Pellizzoni, L. (2004). Responsibility and environmental governance. Environmental Politics, 13(3), pp. 541-565.

Pesch, U. (2015). Engineers and active responsibility. Science and Engineering Ethics, 21(4), pp. 925-939.

Pettit, P. (1997). The Consequentialist Perspective. In: M. Baron, P. Pettit and M. Slote (eds.), Three Methods of Ethics: A Debate. Oxford: Blackwell, pp. 92-174.

Pettit, P. (2015). The Robust Demands of the Good. Ethics with Attachment, Virtue and Respect. Oxford: Oxford University Press.

Pitkin, H. F. (1988). Are freedom and liberty twins? Political Theory, 16(4), pp. 523-552.

Qvortrup L. (2003). The Hypercomplex Society. New York: Peter Lang.

Reber, B. (2016). Precautionary Principle, Pluralism and Deliberation. London: ISTE/ Wiley.

Ricoeur, P. (2000). The Just. Chicago, IL: Chicago University Press.

Ritter, J. (1982). Hegel and the French Revolution. Essays on the Philosophy of Right. Cambridge, MA: MIT Press.

Robinson, D. (2009). Co-evolutionary scenarios: an application to prospecting futures of the responsible development of nanotechnology. Technological Forecasting and Social Change, 76, pp. 1222-1239.

Rodotà, S. (2014). Solidarietà. Un'Utopia Necessaria. Rome: Laterza.

Rosanvallon, P. (2015). Le Bon Gouvernement. Paris: Seuil.

Sartori, G. (1987). The Theory of Democracy Revisited. Chatam, NJ: Chatam House. Seillan, H. (2016). Danger et precaution. Le roman des mots. Paris: Les Belles Lettres-Manitoba.

Sen, A. (1999). Development as Freedom. Oxford: Oxford University Press.

Sen, A. and Williams, B. (eds.), (1982). Utilitarianism and Beyond. Cambridge: Cambridge University Press.

Shapiro, I. (2012). The Moral Foundations of Politics. New Haven, CT: Yale University Press.

Sintomer, Y. (2011). Petite Histoire de l'Expérimentation Démocratique. Paris: La Découverte.

Spaapen, J. (Rapporteur); Strand, R. (Chair); Bauer, M. W., Hogan, E., Revuelta, G. and Stagl, S. (Members); and Paula, L. and Guimarães Pereira, Â. (Contributors) (2015). Indicators for Promoting and Monitoring Responsible Research and Innovation. Report from the Expert Group on Policy Indicators for Responsible Research and Innovation. European Commission. Available at http://ec.europa. eu/research/swafs/pdf/pub_rri/rri_indicators_final_version.pdf

Spämann, R. (1975). Nebenwirkungen als moralisches Problem. Philosophisches Jahrbuch, 82(2), 323.

Stahl, B., Eden, G. and Jirotka, M. (2013). Responsible Research and Innovation in Information and Communication Technology: Identifying and Engaging with 
the Ethical Implications of ICTs. In: R. Owen, J. Bessant and M. Heintz (eds.), Responsible Innovation. Managing the Responsible Emergence of Science and Innovation in Society. Hoboken, NJ: John Wiley, pp. 119-218.

Stilgoe, J., Owen, R. and Macnaghten, P. (2013). Developing a framework for responsible innovation. Research Policy, 42(9), pp. 1568-1580.

Tronto, J. (1993). Moral Boundaries. A Political Argument for an Ethic of Care. London: Routledge.

Turing, A. M. (1950). Computing machinery and intelligence. Mind, 49, pp. 433-460.

Vandamme P.- E. (2018). Le tirage au sort est-il compatible avec l'élection? Revue Francaise de Science Politique, 68(5), pp. 873-894.

:van den Hoven, J. (2013). Value Sensitive Design and Responsible Innovation. In: R. Owen, J. Bessant and M. Heintz (eds.), Responsible Innovation. Managing the Responsible Emergence of Science and Innovation in Society. Hoboken, NJ: John Wiley, pp. 75-83.

van den Hoven, M.J., Lokhorst, G. and van de Poel, I. (2012). Engineering and the problem of moral overload. Science and Engineering Ethics, 18(1), pp. 1-13.

van de Poel, I. (2011). The Relation Between Forward-Looking and BackwardLooking Responsibility. In: N. Vi, I. van de Poel and J. Van den Hoven (eds.), Moral Responsibility, Beyond Free Will and Determinism. Dordrecht: Springer, pp. 37-52.

van Oudheusden, M. (2014). Where are the politics in responsible innovation?

European governance, technology assessments, and beyond. Journal of Responsible Innovation, 1(1), pp. 67-86.

Van Reybrouck, D. (2014). Contre les élections. Arles: Actes Sud.

Villey, M. (1977). Esquisse historique sur le mot responsable. Archives de philosophie du droit, XXII, pp. 45-58.

Vincent, N., van de Poel, I. and Van den Hoven J. (eds.), (2011) Moral Responsibility, Beyond Free Will and Determinism. Dordrecht: Springer.

Von Schomberg, R. (2013). A Vision of Responsible Research and Innovation. In: R. Owen, J. Bessant and M. Heintz (eds.), Responsible Innovation. Managing the Responsible Emergence of Science and Innovation in Society. Hoboken, NJ: John Wiley, pp. 51-74.

Von Schomberg, R. (2014). The Quest for the 'Right' Impacts of Scienceand Technology: A Framework for Responsible Research and Innovation. In: J. Van den Hoven, N. Doorn, T. Swierstra, et al. (eds.), Responsible Innovation 1. Innovative Solutions for Global Issues. Dordrecht: Springer Science and Business Media.

Weil, D., Graham, M. and Fung, A. (2013). Targeting transparency. Science, 340, pp. 1410-1411.

Wickson, F. and Forsberg, E. M. (2015). Standardising responsibility? The significance of interstitial spaces. Science and Engineering Ethics, 21(5), pp. 1159-1180.

Williams, B. (1984). Moral Luck. Albany, NY: Suny Press.

Wojinak, J. (2017). Responsible Research and Innovation. How to put gender equality into practice? Zarzadzanie Publiczne, 38(2), pp. 163-176.

Wynne, B. (1993). Public uptake of science: a case for institutional reflexivity. Public Understanding of Science, 2(4), pp. 321-337.

Wynne, B., Felt, U., Callon, M., Gonçalves, M. E., Jasanoff, S., Jepsen, M., Joly, P. B., Konopasek, Z., May, S., Neubauer, C., Rip, A., Siune, K., Stirling, A. and 
Tallacchini, M. (2007). Taking European Knowledge Society Seriously. Report of the Expert Group on Science and Governance to the Science, Economy and Society Directorate. Directorate-General for Research. European Commission, Brussels.

Zwart, H., Landeweerd, L. and Van Rooij, A. (2014). Adapt or perish? Assessing the recent shift in the European research funding arena from 'ELSA' to 'RRI'. Life Sciences, Society and Policy, 10(11), doi: 10.1186/s40504-014-0011-x 